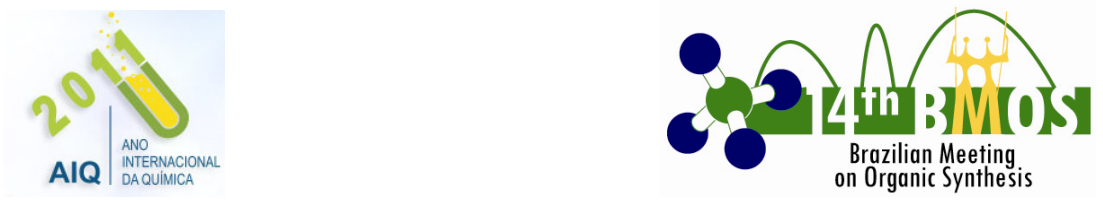

\title{
Synthesis of 7-trifluo[trichlo]romethyl-5-aryl[alkyl]-tetrazolo[1,5-a] pyrimidines in lonic Liquid
}

\author{
Elisandra Scapin*, Lilian Buriol, Clarissa Piccinin Frizzo, Marcos A. P. Martins \\ *scapin@yahoo.com.br
}

Keywords: tetrazolo[1,5-a]pyrimidine, 5-aminotetrazole, ionic liquid

\section{INTRODUCTION}

Tetrazolopyrimidines are important biological agents with a wide range of pharmaceutical (e.g., hyperlipidemia, depression, glaucoma, and cardiac arrhythmias) and agrochemical uses. ${ }^{1}$ The synthesis of this class of compounds by cyclocondensation reaction requires extreme conditions such as the use of acids, high temperatures, and prolonged reaction times. Another drawback for obtaining these compounds is the low yields. Furthermore, the synthesis of trifluoromethylated tetrazolopyrimidine from trifluoromethylated substrates is very limited. ${ }^{2}$ The incorporation of fluorine into a drug allows simultaneous modulation of electronic, lipophilic, and steric parameters, all of which can critically influence both the pharmacodynamic and pharmacokinetic properties of drugs. ${ }^{4}$

In this work, we develop a simple and convenient protocol for the direct synthesis of 7trifluo(trichlo)romethyl-5-aryl(alkyl)-tetrazolo[1,5a]pyrimidine through cyclocondensation of 1,1,1trifluo(trichlo)ro-4-methoxy-3-alken-2-ones and 5aminotetrazole, using ionic liquid.

\section{RESULTS AND DISCUSSION}

The

7-trifluo(trichlo)romethyl-5-aryl(alkyl)tetrazolo[1,5-a]pyrimidines $\mathbf{4 a - i}$, 5a-b were prepared from cyclocondensation reactions between 1,1,1trifluo(trichlo)ro-4-methoxy-3-alken-2-ones 2a-i, 3a-b $(1.0 \mathrm{mmol})$ and 5 -aminotetrazole $1(1.0 \mathrm{mmol})$, in BMIM[BF 4 ] $(1.0 \mathrm{mmol})$ and $\mathrm{HCl}(0.1 \mathrm{mmol})$, at $120^{\circ} \mathrm{C}$, for 6 hours (Figure 1). After the reaction time, the products were extracted with chloroform (5 $\mathrm{mL})$, washed with water $(3 \times 5 \mathrm{~mL})$, and then dried on magnesium sulfate.

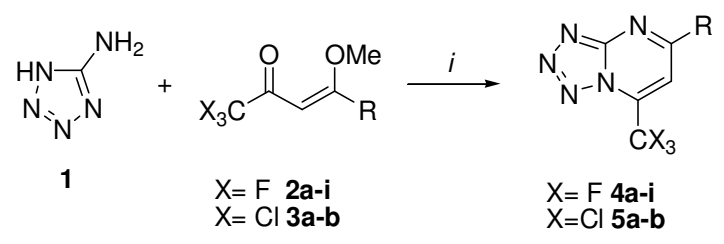

i: $\mathrm{BMIM}\left[\mathrm{BF}_{4}\right], 6 \mathrm{~h}, 120^{\circ} \mathrm{C}, \mathrm{HCl}(0,1 \%)$

Figure 1. Synthesis of 7-trifluo(trichlo)romethyl-5aryl(alkyl)-tetrazolo[1,5-a]pyrimidines 4a-i, 5a-b.

The products were obtained at moderate to good yields in a pure form and without an additional purification step (Table 1). The structure of the 7trifluo(trichlo)romethyl-5-aryl(alkyl)-tetrazolo[1,5a]pyrimidines was determined by ${ }^{1} \mathrm{H},{ }^{13} \mathrm{C}$, $\mathrm{HMBC}$, and HMQC NMR spectroscopy, as well as by X-ray diffraction.

Table 1. Yields of 7-trifluo(trichlo)romethyl-5-aryl(alkyl)tetrazolo[1,5-a]pyrimidines $4 \mathbf{a - i}, \mathbf{5 a - b}$.

\begin{tabular}{|c|c|c|}
\hline Product & $\mathrm{R}^{\mathbf{}}$ & ${\text { yields }(\%)^{\mathrm{a}}}^{\mathrm{a}}$ \\
\hline $\mathbf{4 a}$ & $\mathrm{Ph}$ & 80 \\
\hline $\mathbf{4 b}$ & $4-\mathrm{F}-\mathrm{C}_{6} \mathrm{H}_{4}$ & 97 \\
\hline $\mathbf{4 c}$ & $4-\mathrm{Br}_{4} \mathrm{C}_{6} \mathrm{H}_{4}$ & 90 \\
\hline $\mathbf{4 d}$ & $4-\mathrm{I}-\mathrm{C}_{6} \mathrm{H}_{4}$ & 83 \\
\hline $\mathbf{4 e}$ & $4-\mathrm{Me}-\mathrm{C}_{6} \mathrm{H}_{4}$ & 80 \\
\hline $\mathbf{4 f}$ & $4-\mathrm{OMe}-\mathrm{C}_{6} \mathrm{H}_{4}$ & 89 \\
\hline $\mathbf{4 g}$ & Tien-2-il & 80 \\
\hline $\mathbf{4 h}$ & Biphen-4-yl & 95 \\
\hline $\mathbf{4 i}$ & $\mathrm{CH}_{3}$ & 73 \\
\hline $\mathbf{5 a}$ & $\mathrm{Ph}_{3}$ & 82 \\
\hline $\mathbf{5 b}$ & $\mathrm{CH}_{3}$ & 74 \\
\hline
\end{tabular}

${ }^{a}$ Yield of isolated product.

\section{CONCLUSION}

In summary, our method succeeded in preparing novel 7-trifluo(trichlo)romethyl-5-aryl(alkyl)tetrazolo[1,5-a]pyrimidines through a fast one-step and highly regioselective reaction, using starting materials synthetized in our laboratory. The method is practical and simple, and results in products with moderate to good yields.

\section{ACKNOWLEDGEMENTS}

The authors are grateful to the Conselho Nacional de Desenvolvimento Científico e Tecnológico (CNPq), Fundação de Amparo à Pesquisa do Estado do Rio Grande do Sul (FAPERGS), and CAPES for the financial support and fellowships. \footnotetext{
REFERENCES

${ }^{1}$ Hussein, A. M., Ahmed, O. M., Bioorganic \& Medicinal Chemistry, 2010, 18, 2639.

${ }^{2}$ a) Yao C., Lei S., Wang C., Yu C., and Tu S., J. Heterocyclic Chem., 2008, 45, 1609. b) Chitra S., Devanathan D., and Pandiarajan K., European journal of medicinal Chemistry, 45, 2010, 367. c) Raju, C., Kalaipriya, M., Uma, R., Sridhar, R., Ramakrishna, S., Current Chemistry Letters, 2012, 1, 27.

${ }^{3}$ Krasovskiy, A. L.; Moiseev, A. M.; Nenajdenko, V. G.; Balenkova, E. S., Synthesis, 2002, 7, 901

${ }^{4}$ M. Salwiczek, E.K. Nyakatura, U.I.M. Gerling, S. Ye, B. Koksch, Chem. Soc. Rev., 2012, 41, 213.
} 